\title{
Adequacy of Parking Provisions Based on The Trip Generation Patterns for Urban Commercial Developments
}

\author{
M.R.M. Priyadarshanie' H.R.Pasindu, S.W.M.P.Senevirathne, and D.N.D.Jayaratne
}

\begin{abstract}
Urban commercial developments are an integral part of the urban land use which affect the trip generation and attraction pattern in the city. More importantly, these developments increase the demand for parking, which by law should be provided within the development. Lack of adequate parking facilities will impact the road network as it will lead to onstreet parking and additional vehicular circulation to and from public car parking areas. Furthermore, provision of parking within the premises results in an increase in the cost to the developer which can escalate the prices of the property. Therefore, regulations need to ensure that adequate number of parking are stipulated based on the type of facility. Parking regulations for office building type developments used for the city of Colombo are based on gross floor area of the building, which may not necessarily represent the parking needs of the building depending on the type of operation which takes place. Therefore, the existing parking regulations for these types of development need to be revised in order to assess the optimal parking requirement for different types of office buildings. The research aims to evaluate the trip generation patterns for different types of office developments. Based on the study results parking demand and trip attraction rate will be assessed..
\end{abstract}

Index Terms - Accessibility, land use, parking demand, parking requirement, trip attraction.

\section{INTRODUCTION}

$T^{1}$ he development of commercial activities especially in urban areas have directly affected to the increase in trip generation and attraction pattern in cities. Each and every person starts and ends their trips as pedestrians excluding exceptional trips. In terms of trips using private automobiles, the pedestrian portion of the trip starts or ends at a parking space. Therefore, increment of trip generation and attraction patterns has led to the demand of parking, which should be provided within the development. Therefore, with reference to the demand more parking spaces should be allocated. But it has been recognized that the existing parking capacity of on and off street does not appear to adequately meet the demand. Therefore, lack of adequate parking facilities has a direct influence on the road network as it has led to on-street parking and additional vehicular circulation to and from public car

M.R.M. Priyadarshanie is with the Department of Civil Engineering, University of Moratuwa, 10400, Sri Lanka (e-mail: mrmadarap@gmail.com)

H.R.Pasindu is with the Department of Civil Engineering, University of Moratuwa, 10400, Sri Lanka parking areas. Moreover, provision of parking within the premises results in an increase in the cost to the developer which can escalate the property prices [1,2]. L.R. Kadiyali [1] has clearly mentioned one of the problems created by road traffic is parking. In addition to that it has mentioned ill- effects of parking as congestion, accidents, obstruction to firefighting operations and Environment. The city of Annapolis, Parking utilization analysis [3] has also mentioned the lack of adequate parking result in driver frustration, traffic congestion and illegal parking actions affecting public safety. Traditionally parking requirement for development is calculated based on the parking code stipulated in the city parking ordinance and calculation is formulated by considering on gross floor area. [4]. T. Litman [5] has mentioned conventional parking standards are based on the parking demand surveys but thing is these conventional parking standards are extortionate where parking is shared or priced. Therefore, regulations need to ensure adequate number of parking are stipulated based on the type of facility.

In the Sri Lankan context, Urban Development Authority is one of the responsible institutions that regulate and enforce parking requirements and the parking allocation depends on the type and size of land use in a development.

The main objective of this study is to develop a model to estimate trip attraction and peak parking demand for office developments. Therefore, the study focuses on factors which are affected for the parking requirement such as floor area, working population and service population. Scope of the study is defined on urban office developments within Colombo municipal council area under the commercial land use setting.

\subsection{Factors Affecting for parking requirement}

As per R.P.Roess et al [6], T.V.Mathew [7], M. Pitsiava Latinopoulou et al [8] and A. Milne [9] mentioned that the main factors affecting the parking requirement are as follows,

- Floor area

- Employees

- Site area

- Service population

- Parking volume

- Parking load 


\section{Methodology}

The items in the full scale version of Driving Anger Scale [26], if grouped into six clusters were as follow (S indicates item in short scale version; I indicates selected item for Indonesian version):

\subsection{Data Collection}

The data were obtained by In \& Out surveys and Questionnaire surveys to a sample of 30 office buildings in Colombo Municipal Council Area, Sri Lanka. The in \& Out surveys were conducted on weekdays from 06:00 to 18:00 hours in both government and private office buildings. Data collection included parking volume, available parking slots, Gross Floor area of the building, No of employees, No of service population, Parking occupancy rate, Parking load, type of vehicle and purpose of the trip. The questionnaire survey was directly delivered for employees and customers by using an oral question formulation. In-Out surveys were conducted coupled with the license plate method survey. First, the vehicles that enter to the building were counted and license plate numbers were noted for a particular time and the same process was continued for the vehicles that leave from the building. The common issues noted during the surveys are as follows,

- Most of the office buildings have allocated parking only for office use and not for visitors or beneficiaries.

- Most offices use roadside parking

- Some parking spaces are not fully occupied and some parking spaces are over occupied due to lack of proper management.

\subsection{Sample Selection}

150 office buildings were identified using Geographic Information System (GIS) which was created by Urban Development Authority for Colombo Municipal council area. Then sample selection was carried out by considering building ownership, condition and status of all 150 buildings. Subsequently, considering the floor area, the buildings were classified into 3 categories using GIS: Geometric Interval Analysis. The $30 \%$ sample was selected representing each classified level for the study.

TABLE I

LEVELS CLASSIFICATION

\begin{tabular}{ll} 
& LEVELS CLASSIFICATION \\
\hline Level & Floor Area \\
\hline 1 level & $0-1500$ sq. $\mathrm{ft}$ \\
2 level & $1500-15000$ sq. $\mathrm{ft}$ \\
3 level & $15000-165000$ sq. $\mathrm{ft}$ \\
\hline
\end{tabular}

\subsection{Analytical Approach}

The parking terminology used in the study is describes as follow $[1,7]$

\subsubsection{Parking Volume}

The number of vehicles parked in a particular area over a given period of time. It usually measured in vehicles per day.

\subsubsection{Parking load}

The total number of vehicles parked in an area at a specified moment obtained by multiplying the number of vehicles occupying the parking area at each time interval with the time interval.

\subsubsection{Average Parking Duration}

It is the ratio of total vehicle hours to the number of vehicles parked.

$$
\text { Average parking duration }=\frac{\text { Parking load }}{\text { Parking volume }}
$$

\subsubsection{Parking turnover}

It is the ratio of a number of vehicles parked during a particular time interval to the number of parking bays available.

$$
\text { Parking turnover }=\frac{\text { Parking volume }}{\text { No of bays available }}
$$

\subsubsection{Parking Index}

It is defined as the ratio of a number of bays occupied in a time duration to the total space

available. Parking index is called as occupancy or efficiency.

$$
\text { Parking Index }=\frac{\text { Parking load }}{\text { Parking Capacity }} * 100
$$

\subsubsection{Application of Geometrical Interval Analysis}

This method created class ranges based on intervals that have a geometric order based on a multiplier (and its inverse). It produced these intervals by minimizing the square sum of elements per class, this ensures that each interval has an appropriate number of values within it and the intervals are similar. This algorithm was designed to accommodate continuous data. [10]

\subsubsection{Regression Analysis}

SPSS software is used to identify the influence between dependent and independent variables (Correlation). It used to select parameters, which have a strong relationship with daily trip attraction (dependent variable) and peak parking demand (dependent variable) and three independent variables were selected for the analysis. [1,11] Then Multiple linear regression is used for the establishment of a relationship between dependent and independent variables

\section{DATA ANALYSIS AND RESUltS}

\subsection{Survey Data Analysis}

\subsubsection{Distribution of Daily trip attraction}

Daily trip attraction is an important indicator to understand trip attraction behaviour to office buildings. Fig. 1 shows the arrival of vehicle trip attractions from 06:00 to 18:00 hours. This consists of the total number of trips which are attracted to the office and the number of trips which are generated from the office. 


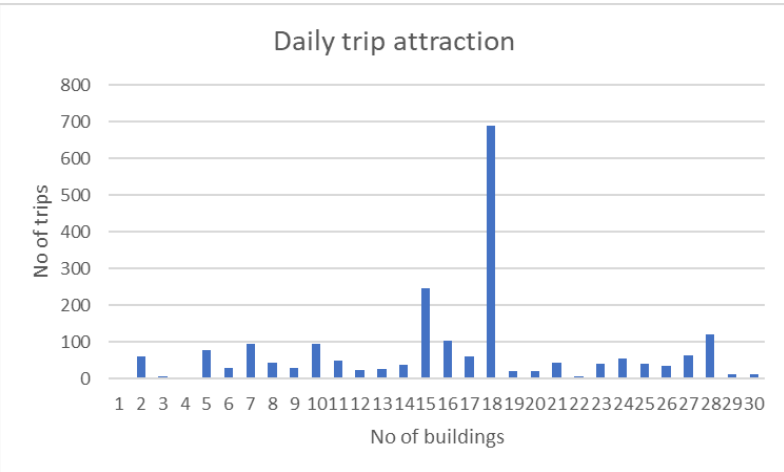

Fig. 1. Statistical distribution of daily trip attraction

\subsubsection{Parking Volume}

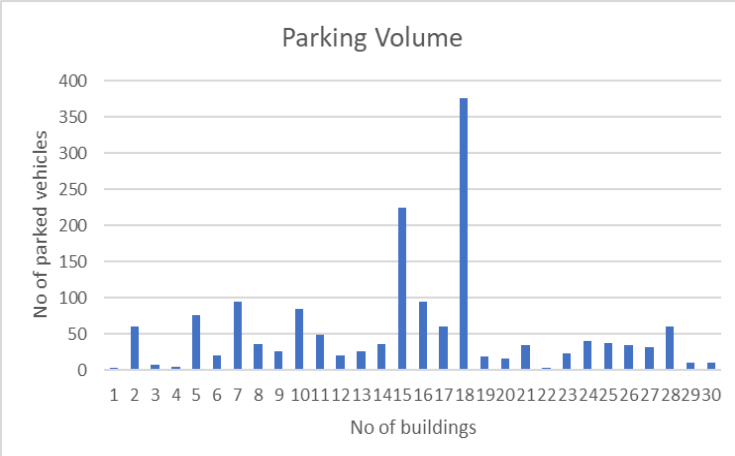

Fig. 2. Statistical distribution of parking volume

Fig.2 shows the number of vehicles parked in the office premises during a specific time period of a day. The parking volume is counted excluding drop off and pick up vehicles.

\subsubsection{Total parking duration}

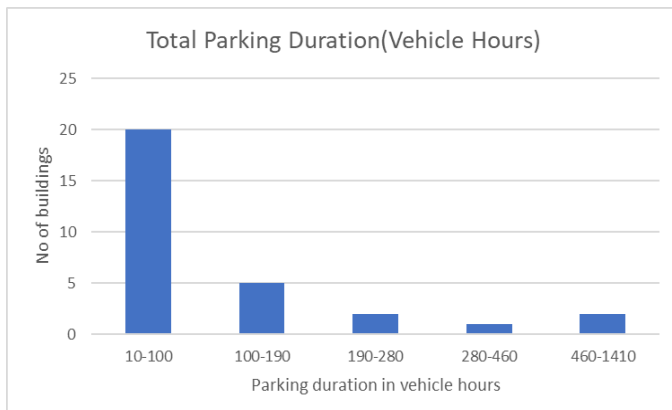

Fig. 3. Statistical distribution of total parking duration

Fig. 3 shows the total parking duration in hours. It was calculated by using In \& Out surveys. The results perform that about $66 \%$ of vehicles are used to parked during 10 to 100 -hour time period.

\subsubsection{Parking turnover}

Fig.4 demonstrates the frequency of occupation of a parking slot within the considered time period. The result indicates that in average a parking slot is being occupied 1-3 times per a day in an office building.

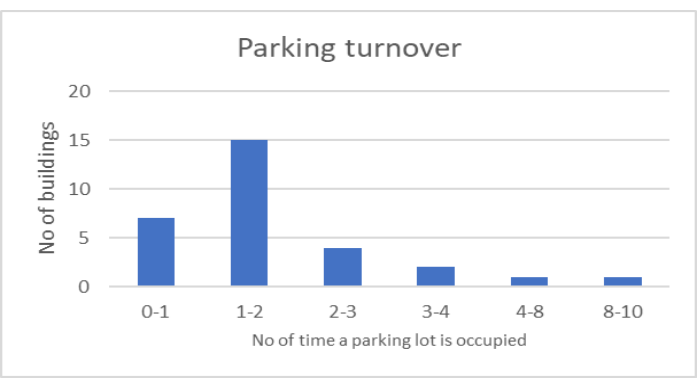

Fig. 4. Statistical distribution of Parking turnover

\subsubsection{Parking Index}

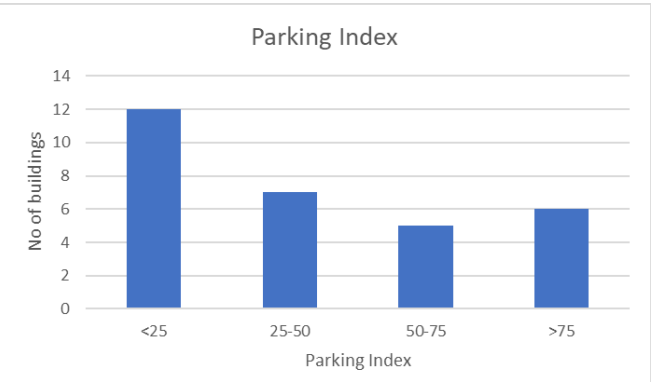

Fig. 5. Statistical distribution of Parking Index

Parking index, Fig.5 is used to identify as the utilization rate of the provided parking slots. Out of the 30 buildings sample two buildings have reached $100 \%$ parking index and two buildings are beyond their parking capacity. These buildings have 9 and 7.5 parking turn over values. Utilization of parking below $50 \%$ indicates that the buildings have excess parking facilities. In this graph, $65 \%$ of the data are below $50 \%$. Therefore, it clearly indicates that there is a mismatch in the parking requirement and parking allocation.

\subsubsection{Distribution of trips by mode}

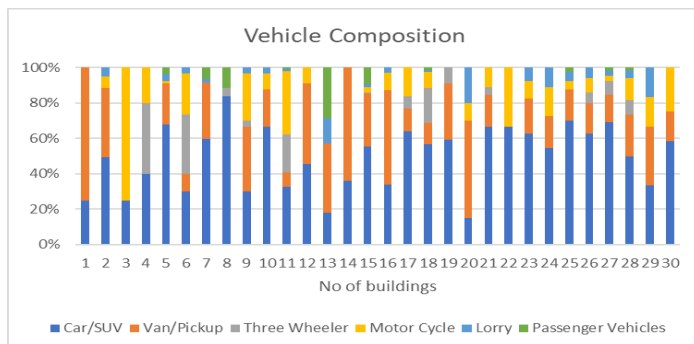

Fig. 6. Statistical distribution of trips by mode

Fig. 6 demonstrates that $55 \%$ of the employees and visitors use cars as their mode of transportation rather than selecting other transportation modes. In addition to that dual-purpose vans, pickup trucks and motorcycles are getting a prominent place.

\subsubsection{Distribution of trips by type}

Fig.7 illustrates type of vehicles used to travel to the office building. Term of office vehicles can be defined as vehicles which are owned by a particular office. Type of official vehicles are the vehicles which are used to travel from one office to 
another for official purposes. Customer vehicles are very less because most of the office buildings are not direct service providers for customers.

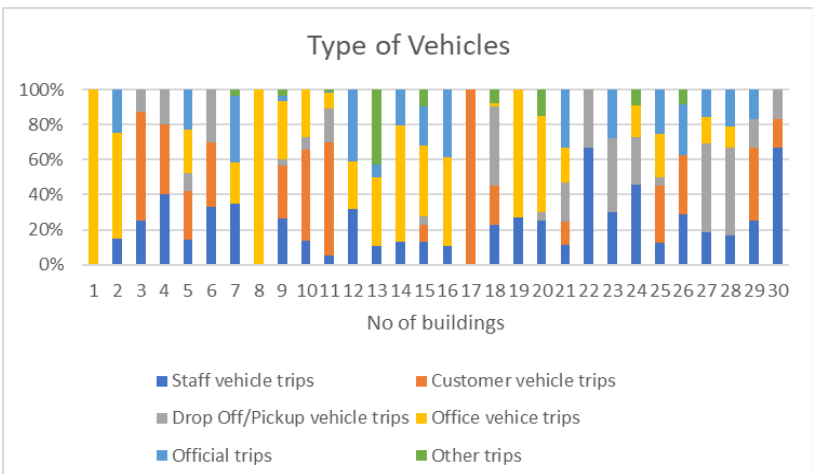

Fig. 7. Statistical distribution of trips by type of vehicles.

\subsubsection{Trip attraction vs Parking volume}

Fig.8 demonstrates the distribution of daily trips and parking volume. It shows that all the attracted trips do not using parking, as drop-off and pickup vehicles are not counted as parked vehicles. Another thing is that most of the office parking slots are not allowed for customers. So, the situation is, those trips were counted but it was not counted as parked vehicles.

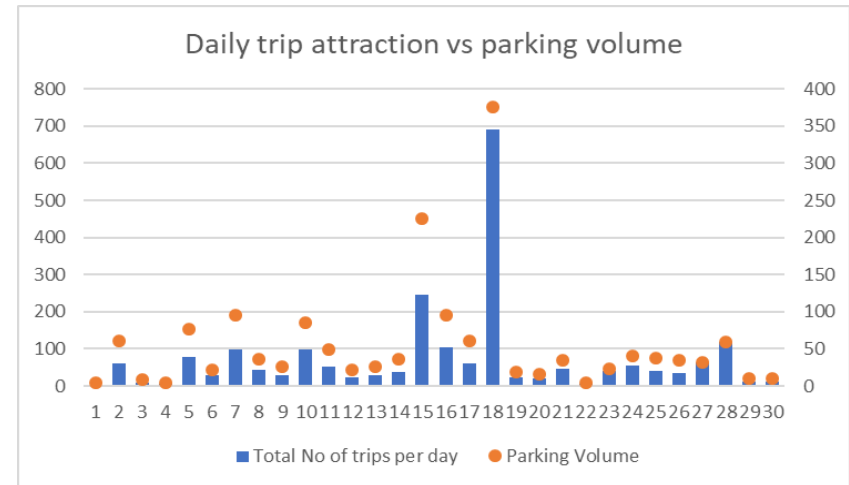

Fig. 8. Comparison of trip attraction vs parking volume

3.1.9 Behavioral pattern of dependent (daily trip attraction) and Independent variables (Floor area, employees, service population)

Fig. 9 interprets the behavioral distribution of no of daily trips with floor area. $\mathrm{R}^{2}$ value of this distribution is 0.3168 and it shows positive linear relationship between daily trips and floor area.

Behavioral distribution of No of daily trips with No of Employees are shown in the fig. 10. The relationship between these two variables show positive linear relationship and it shows $\mathrm{R}^{2}$ value is 0.4931 . Moreover, all the data points are gradually scattered and selected two variables show a strong correlation.

Fig. 11 interprets the Behavioral distribution of daily trips with Service population. The relationship between these two variables are showing $0.423 \mathrm{R}^{2}$ value. It illustrates that daily trips and service population have positive linear relationship.

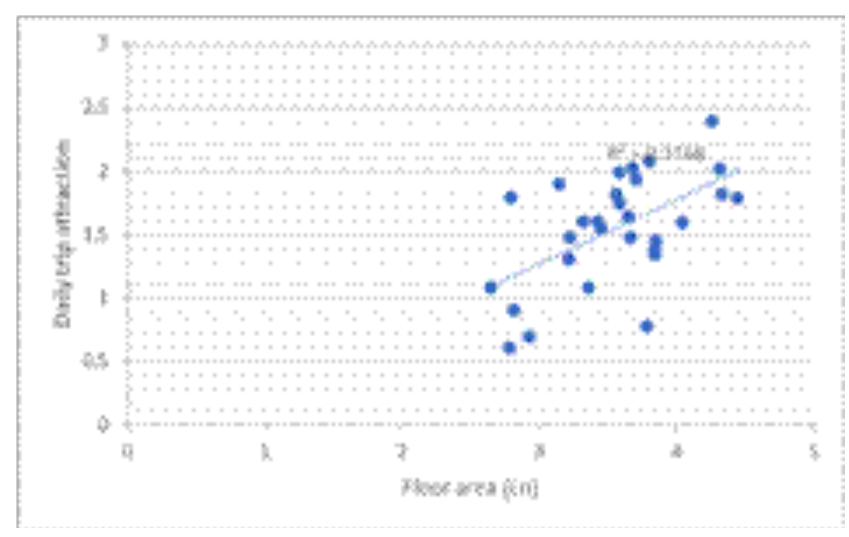

Fig.9. Scatter plot of trip attraction vs floor area

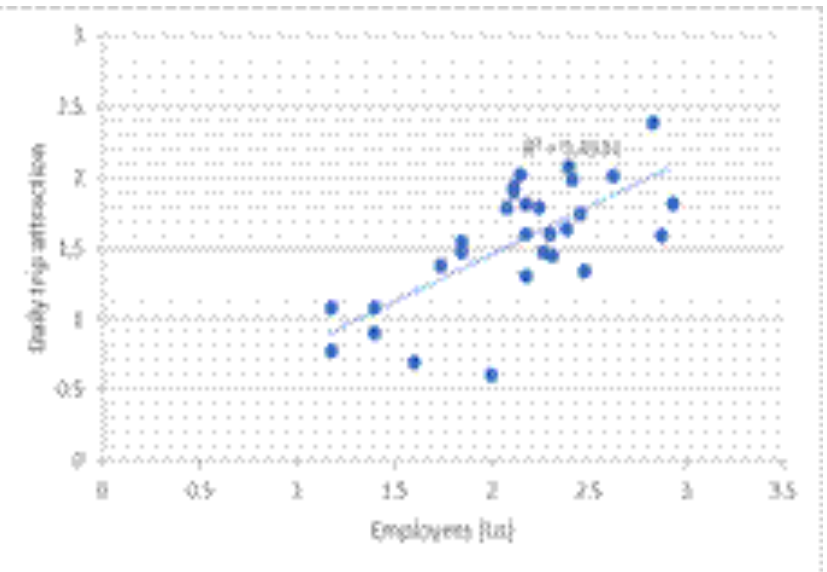

Fig.10.Scatter plot of trip attraction vs employees

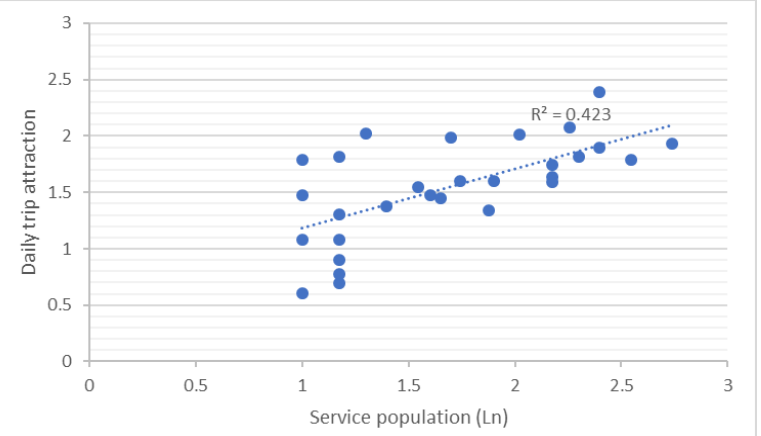

Fig. 11. Scatter plot of trip attraction vs service population

3.1.10 Behavioral pattern of dependent (peak parking demand) and Independent variables (Floor area, Employees, service population)

Behavioral distribution of peak parking demand with floor area is shown in Fg.12. It shows a positive, linear relationship of strong strength between selected two variables. The $\mathrm{R}^{2}$ value is 0.2565 . 


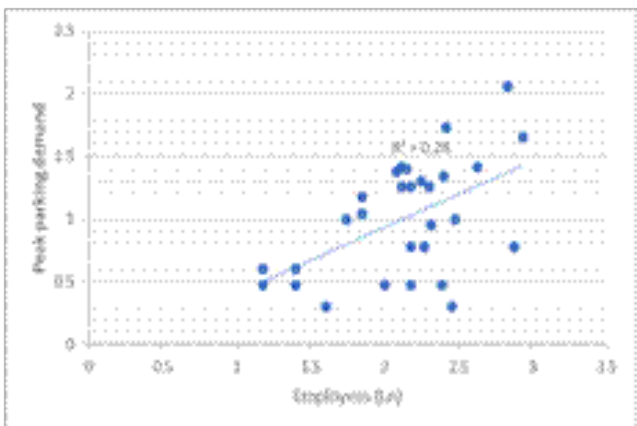

Fig.12. Peak Parking demand vs Floor area

Fig.13 interprets the behavioral distribution of peak parking demand with No of Employees of the selected buildings. $\mathrm{R}^{2}$ shows 0.28 value with a positive, linear relationship between selected variables.

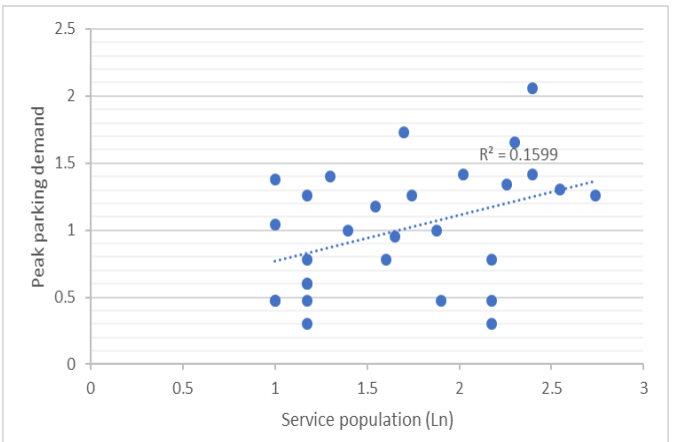

Fig.13. Peak Parking demand vs Service population

Fig. 14 illustrates the behavioral distribution of peak parking demand with service population and it earned $0.1599 \mathrm{R}^{2}$ value with the moderate, linear relationship between selected two variables.

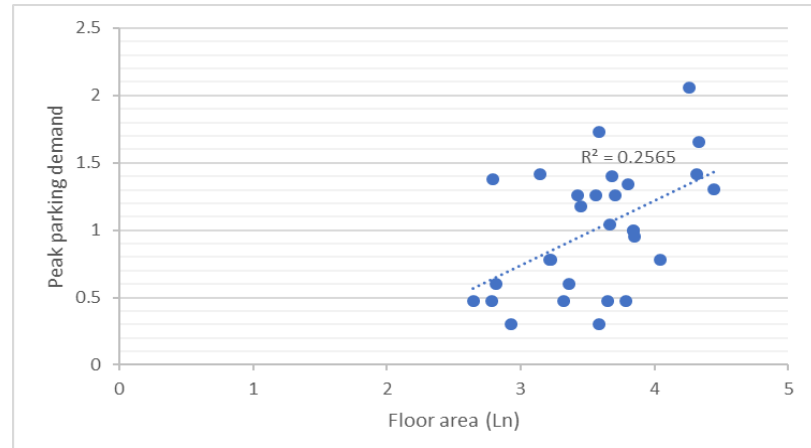

Fig. 14. Peak parking demand vs service population

\subsection{Model Formulation}

To formulate the model a regression analysis was used on the data set which was collected using In \& out survey. The derived two formulas are applied to estimate daily trip attraction and peak parking occupancy for the office buildings.

\subsubsection{Modal formulation: Daily trip Attraction}

To formulate the trip attraction model, no of employees and services population has been selected as an independent variable by considering previous $\mathrm{R}^{2}$ value results of behavioral pattern of dependent and independent variable.

To formulate the peak parking demand model, no of employees and gross floor area has been selected as independent variables by considering previous $\mathrm{R}^{2}$ values of behavioral pattern of dependent and independent variable.

TABLE II

MODEL COEFFICIENTS

\begin{tabular}{|c|c|c|c|c|c|}
\hline \multirow[t]{2}{*}{ Modal } & \multicolumn{2}{|c|}{ Unstandardized Coefficients } & \multirow{2}{*}{$\begin{array}{l}\begin{array}{c}\text { Standardized } \\
\text { Coefficients }\end{array} \\
\text { Beta } \\
\end{array}$} & \multirow[t]{2}{*}{$\mathrm{t}$} & \multirow[t]{2}{*}{ Sig } \\
\hline & $\mathrm{B}$ & Std. Error & & & \\
\hline 1 (Constant) & 12.266 & 11.028 & & .765 & .451 \\
\hline No of Employees & .164 & .030 & .558 & 5.380 & .000 \\
\hline Service population & .302 & .067 & .467 & 4.505 & .000 \\
\hline
\end{tabular}

a. Dependent Variable: Total No of trips per day

The formulated model has obtained $0.774 \mathrm{R}^{2}$ value with a positive, linear relationship of strong strength between dependent and independent variables and sig value of the independent variables are less than 0.05 .

The formulated daily trip attraction model is as follows,

Daily trip attraction $=12.266+\left[\left(0.164^{*}\right.\right.$

No of employees $)+(0.302 *$ service population $)]$

\subsubsection{Model formulation: Peak parking demand}

The formulated model has obtained $0.751 \mathrm{R}^{2}$ value and it shows positive, linear relationship of strong strength between predictors and dependent variable. Moreover, the model has obtained .033 and .000 significant values which are less than 0.05 . The formulated model for Peak parking demand is as follows:

Peak Perking Demand $=7.765+\left[\left(0.026^{*}\right.\right.$ No of employees $)+(0.001 *$ floor area $)]$ 
TABLE III

MODEL COEFFICIENTS

\begin{tabular}{|l|l|l|l|l|c|}
\hline \multirow{2}{*}{ Modal } & \multicolumn{2}{|c|}{$\begin{array}{c}\text { Unstandardized } \\
\text { Coefficients }\end{array}$} & $\begin{array}{l}\text { Standardized } \\
\text { Coefficients }\end{array}$ & \multirow{2}{*}{ Sig. } & \\
\cline { 2 - 4 } & $\mathrm{B}$ & Std.Error & Beta & & \\
\hline 1 (Constant) & 7.765 & 4.214 & & 1.843 & .076 \\
\hline No of Employees & .026 & .012 & .334 & 2.252 & .033 \\
\hline Floor area & .001 & .000 & .590 & 3.980 & .000 \\
\hline
\end{tabular}

a. Dependent Variable: Peak Parking demand

\subsubsection{Relationship between Trip attraction and Peak parking demand}

Parking demand and no. of trip generation can be identified as important determinants in deciding the parking allocation. To identify the relationship between the two factors curve estimation analysis was carried out. It was carried out for the following curves, as per linear, power, S, Growth and exponential. the best fit curve with an $\mathrm{R}^{2}$ value of 0.586 was found as a power curve.

The power curve represents that the trip generation and parking demand has a positive but gradually declining relationship with the increment of the value in the x- axis. The parking demand keeps increasing with the increment in the no. of trip attraction and gradually it aligns to the $\mathrm{x}$-axis having equivalent to a constant value with the further increment in the no of trip attraction.

This behavior can be observed as the number of parking requirement is distributed among the building functional hours where the peak demand becomes similar in higher trip attraction scenarios. According to the results, the parking turnover can be a higher value at high trip attraction scenarios where the parking index value shall stay below $100 \%$. The curve gives an $R^{2}$ value of 0.762 for the exponential curve between the trip attraction and peak parking demand.

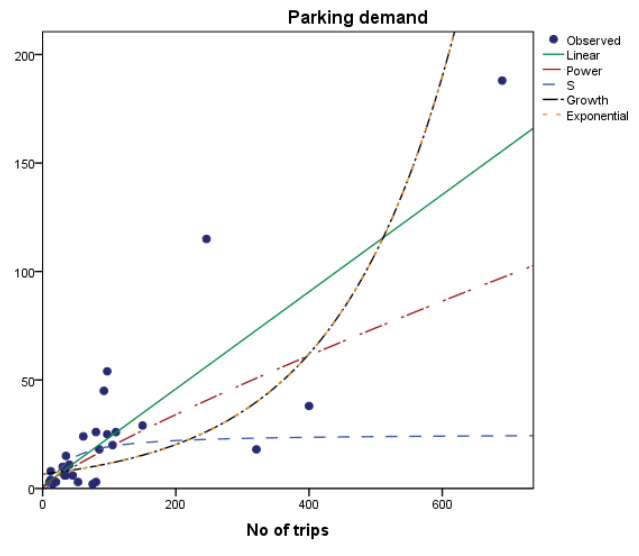

Fig. 15. Relationship between daily trip attraction and peak parking demand

\section{CONCLUSIONS}

The study proposes a simple methodology to evaluate the adequacy of parking provisions based on the trip generation patterns for urban office developments. The conventional method for estimating parking requirement is based on the development plan: parking requirement which was developed by Urban Development Authority and the only variable considered for that was floor area. There is no prediction on how many trips will be attracted for a certain development. They identified the floor area of the building and allocate parking according to the development plan used in the particular location.

In this study, first, factors which affected the trip attraction Here identified and based on that the analysis was carried out. And it has identified that the no of employees and service population have a direct influence on trip attraction pattern. Therefore, trip attraction model was developed based on the independent variables which have a significant influence on those aspects. Secondly peak parking demand was estimated by considering the floor area and no of employees. The peak parking demand is defined as no of parking slots that should be allocated for the development. Moreover, it has selected no of employees as an influencing variable in addition to the floor area. That will eliminate parking over usage and roadside parking issues.

One of the limitations of this model was most of the office buildings selected are not direct service providers for the customers. Therefore, there was a lesser number of service population except for few office buildings.

Generally, the developed model can be used to estimate daily trip attraction for the office building and to estimate peak parking demand (parking allocation). Ultimately, the developed model concludes that the parking demand has a positive relationship with the no. of trip attraction (power curve $\mathrm{R}^{2} 0.586$ and the amount gets gradually declined with the increment in the trip attraction.

\section{REFERENCES}

[1] L.R. Kadiyali, "Traffic Engineering and Transport Planning, $7^{\text {th }}$ Edition," 2007.

[2] D.C.Shoup, "The trouble with minimum parking requirements," Transportation Research Part A: Policy and Practice 33, no. 7-8: 549574, 1999.

[3] City of Annapolis, "Parking Utilization Analysis," June 30, 2017.

[4] G.K.Kuah, "Estimating Parking Demand for Mixed-Use Developments Subject to TSM Ordinances," ITE Journal 61, no. 2: 19-24, 1991.

[5] T.Litman, "Parking Management Stragegies, Evalution and Planning," Victoria Transport Policy Institute, 2006.

[6] R.P.Roess, E.S.Prassas, and W.R.Mcshane "Traffic Engineering, 4th Edition," New York University, 2004.

[7] T.V.Mathew, "Transportation Syestems Engineering, Parking Studies," IIT Bombay, 2014.

[8] M. Pitsiava Latinopoulou, G.Tsohos, and S.Basbas, Transact. On. The. B Environ. 52, 298-306, 2001.

[9] A.Milne, S.Abley, and M.Douglass, "Comparisons of NZ and UK trips and parking rates," Land Transport NZ Research Report 374118 pp. 2009.

[10] V.Pappas, "Data classification methods in GIS," University of Thessaly, Department of Planning and Regional Development, 2013.

[11] Anon, "An introduction to multiple regression performing a multiple regression on SPSS," 2008. 